\title{
Physician based surveillance system for occupational respiratory diseases: the experience of PROPULSE, Québec, Canada
}

Montréal Public Health Department, Occupational and Environmental Health Unit

$S$ Provencher

F P Labrèche

L De Guire

Correspondence to: Dr Simone Provencher, Montréal Public Health and Environmental Health Unit, 75 de Port-Royal East, Room 240, Montréal,

Québec, Canada, H3L 3T1.

Accepted 20 November 1996

Simone Provencher, France P Labrèche, Louise De Guire

\begin{abstract}
Objective-To evaluate the feasibility of implementing a physician based surveillance system of occupational respiratory diseases (PROPULSE) in Québec with regard to physician participation rate, characteristics of reported cases, and comparison with official statistics from the Workers' Compensation Board (WCB).

Methods-All chest physicians and allergists in Québec were asked to report suspected new cases of occupational respiratory diseases, on a monthly basis, between October 1992 and September 1993. For each case, personal information was collected and the physician's opinion on whether the condition was related to work was categorised as highly likely, likely, and unlikely.
\end{abstract}

Results-Of the 161 physicians initially approached, 68\% participated. Physicians rated $48 \%$ of suspected cases as highly likely, $29 \%$ as likely, and $20 \%$ as unlikely. The most often reported diagnosis was asthma (63\%), followed by diseases related to asbestos (16\%). Silicosis was less frequent (5\%) but it was reported for six workers under 40 of whom five were involved in sandblasting activities. The high proportion of cases of asthma probably reflects the increasing importance of this disease but may also reflect the different patterns of reporting among physicians with different expertise. The distribution of cases by diagnostic category is quite different between the PROPULSE system and that of the WCB (annual mean number of compensated cases during a four year period). Asthma and allergic alveolitis are more frequent in PROPULSE, reactive airways dysfunction syndrome are about the same in both systems, and other diseases are more frequent among compensated cases. The most frequent sensitising agents reported for asthma were the same in both systems (isocyanates, flour, and wood dust). 15\% of the PROPULSE cases were not covered by the WCB, and therefore would not be found in the board's official statistics. Conclusions-A physician based reporting procedure can be implemented as part of a surveillance system to supplement data from other sources and thus provide a better understanding of the occurrence of occupational respiratory diseases.
(Occup Environ Med 1997;54:272-276)

Keywords: surveillance system; occupational respiratory diseases; occupational asthma

Occupational respiratory diseases have been recognised since the 16th century. ${ }^{1}$ Despite the preventable nature of most of these disorders, workers continue to develop work related respiratory problems. In the province of Québec, Canada, information on the occurrence of these diseases comes from statistics on disability benefits, available from the Québec Workers' Compensation Board (WCB). These data, although useful, have some limitations and do not present a complete picture of the situation. Some affected workers may not apply for compensation or some may give up before the completion of the workers' compensation procedures leading to recognition of an occupational disease.

To develop other means of surveillance of these types of illnesses, a few physician based surveillance systems have been established in the past few years: SWORD in the United Kingdom $^{23}$ and a Registry in British Columbia, Canada ${ }^{4}$ for occupational respiratory diseases; SHIELD ${ }^{5}$ in the West Midlands Region of the United Kingdom for occupational asthma; and SENSOR in the United States for several occupational conditions including silicosis and asthma. ${ }^{67}$ Our project PROPULSE (PROjet PULmonaire SEntinelle) was developed along the same model as the SWORD project with similar reporting procedures, the same diagnostic categories but different types of physicians. Chest physicians were part of both systems but occupational physicians participated in SWORD and allergists in PROPULSE.

The general aim of our project was to develop a system for monitoring occupational respiratory diseases in Québec, so as to better estimate their incidence, to provide information earlier in the course of the disease, and to identify workplaces toward which public health interventions could be targeted. A pilot study was conducted to evaluate the feasibility of implementing a network of sentinel physicians to report diseases on a voluntary basis. The objectives of the pilot study were: $(a)$ to determine the rate of response among participating physicians; $(b)$ to analyse data from reported cases and describe their characteristics, to find their usefulness for surveillance of these diseases in Québec public health; and $(c)$ to estimate underreporting of cases to the WCB. 


\section{Methods}

Every chest physician and allergist registered with the College of Physicians of Québec (the licensing body) was identified. Physicians that would not normally see occupational cases (paediatricians, retirees, researchers, etc) were excluded. The remaining 161 physicians were asked to participate in the network of sentinel physicians. They comprised 135 chest physicians and 26 allergists. They were instructed to report, early in the course of investigation, every new case of respiratory disease that they suspected could be related to work. They had to notify these cases between 1 October 1992 and 30 September 1993.

The first reporting form was sent to these physicians with instructions on how to complete the form and a list of occupations, industries, and causal agents most often associated with each disease. Afterwards, they were sent a monthly reporting form to be returned whether or not they had seen cases. A postal reminder was sent to non-respondents. The most common diagnoses were listed on the reporting form with an open space left for specifying any other occupational respiratory disorder.

For each case, information was collected on age, sex, tobacco smoking, worker's occupation, type of industry, causal agent suspected by the reporting physician, and whether the patient was covered by the WCB (not mandatory for self employed workers, such as many agricultural workers). The physician's opinion was solicited on whether the condition was related to work, categorised as highly likely, likely and unlikely. Finally, to detect duplicate reports, we asked for the patient's initials and his or her city of residence.

The worker's occupation and type of industry were coded according to classifications developed by Statistics Canada. ${ }^{89}$ Data from surveys carried out by Statistics Canada were used to estimate rates of occupational asthma in the working population by age, sex, and type of industry. ${ }^{1011}$ Confidence intervals (CIs) were calculated for rates by industry based on the Poisson distribution. ${ }^{12}$

Table 1 Cases and proportions by diagnostic category for all cases and by sex

\begin{tabular}{|c|c|c|c|c|}
\hline \multirow[b]{2}{*}{ Diagnostic category } & \multicolumn{2}{|l|}{ All cases } & \multirow[b]{2}{*}{$\begin{array}{l}\text { Men } \\
n(\%)\end{array}$} & \multirow[b]{2}{*}{$\begin{array}{l}\text { Women } \\
n(\%)\end{array}$} \\
\hline & $n(\%)$ & $\begin{array}{l}\text { Mean age } \\
\text { (y) }\end{array}$ & & \\
\hline Asthma & $287(63 \cdot 4)$ & $38 \cdot 8$ & $205(71 \cdot 4)$ & $82(28 \cdot 6)$ \\
\hline Silicosis & $25(5 \cdot 5)$ & $56 \cdot 7$ & $25(100 \cdot 0)$ & $0(0.0)$ \\
\hline Benign pleural disease & $25(5 \cdot 5)$ & $60 \cdot 1$ & $25(100 \cdot 0)$ & $0(0.0)$ \\
\hline Allergic alveolitis & $24(5 \cdot 3)$ & $35 \cdot 9$ & $20(83 \cdot 3)$ & $4(16 \cdot 7)$ \\
\hline Mesothelioma & $19(4 \cdot 2)$ & $63 \cdot 1$ & $19(100 \cdot 0)$ & $0(0.0)$ \\
\hline Asbestosis & $19(4 \cdot 2)$ & $65 \cdot 6$ & $18(94 \cdot 7)$ & $1(5 \cdot 3)$ \\
\hline Inhalation accident (RADS) & $14(3 \cdot 1)$ & $41 \cdot 1$ & $12(85 \cdot 7)$ & $2(14 \cdot 3)$ \\
\hline Sick building syndrome & $11(2 \cdot 4)$ & $44 \cdot 5$ & $4(36 \cdot 4)$ & $7(63.6)$ \\
\hline Inhalation accident (others) & $7(1 \cdot 5)$ & $48 \cdot 6$ & $6(85 \cdot 7)$ & $1(14 \cdot 3)$ \\
\hline \multirow{2}{*}{$\begin{array}{l}\text { Lung or bronchial cancer } \\
\text { without fibrosis } \\
\text { Chronic bronchitis }\end{array}$} & $6(1 \cdot 3)$ & $64 \cdot 0$ & $6(100 \cdot 0)$ & $0(0.0)$ \\
\hline & $4(0.9)$ & $48 \cdot 2$ & $2(50 \cdot 0)$ & $2(50 \cdot 0)$ \\
\hline \multirow{5}{*}{$\begin{array}{l}\text { Lung or bronchial cancer } \\
\text { with fibrosis } \\
\text { Byssinosis } \\
\text { Infectious diseases } \\
\text { Others }\end{array}$} & & & & \\
\hline & $2(0 \cdot 4)$ & $72 \cdot 5$ & $2(100 \cdot 0)$ & $0(0 \cdot 0)$ \\
\hline & $1(0 \cdot 2)$ & N/A & $1(100 \cdot 0)$ & $0(0 \cdot 0)$ \\
\hline & $0(0 \cdot 0)$ & - & $0(0 \cdot 0)$ & $0(0.0)$ \\
\hline & $9(2 \cdot 0)$ & $41 \cdot 3$ & $7(77 \cdot 8)$ & $2(22 \cdot 2)$ \\
\hline Total & $453(100 \cdot 0)$ & $44 \cdot 0$ & $352(77 \cdot 7)$ & $101(22 \cdot 3)$ \\
\hline
\end{tabular}

$\mathrm{N} / \mathrm{A}=$ not available
Nominal comparison with compensated cases had not been planned at this feasibility stage of the reporting system. We estimated the amount of underreporting by the WCB as follows: cases considered by reporting physicians from PROPULSE as highly likely to be related to work were compared with the annual mean number of compensated cases during a four year period (1991-4) (WCB, unpublished data, 1995.)

\section{Results}

REPORTING SYSTEM

Of the 161 physicians initially approached, $68 \%$ participated with at least one return over the 12 months of the study; $57 \%$ returned at least nine monthly forms, whereas $23 \%$ returned the form every month. The final network included 92 chest physicians and 18 allergists. The frequency of monthly returns remained steady during the year, varying from $60 \%$ to $70 \%$, showing that interest of the physicians did not decline over time. A small percentage of physicians (16\%) reported $60 \%$ of cases, whereas $61 \%$ of participating physicians reported all the cases.

CHARACTERISTICS OF CASES

Men constituted more than three quarters of cases, and mean age varied according to diagnostic category (table 1), younger cases being diagnosed with short latency diseases. The proportion of men was always larger than that of women, except for sick building syndrome. This was expected, given the larger participation of men in the industrial sectors most often associated with occupational respiratory diseases. ${ }^{10}$ (Statistics Canada, unpublished data) The proportion of smokers $(26 \%)$ was low compared with the general population of Québec $(29 \%-33 \%)^{13}$ and this can possibly be explained by respiratory symptoms that convinced cases to stop smoking. The proportion of non-smokers $(47 \%)$ is higher than expected ( $41 \%$ in the general population) and this may be due to the varying definitions of this category of tobacco consumption across different surveys, and to a possible tendency to deny tobacco consumption among patients who are light or ex-smokers.

Physicians considered the disease highly likely to be related to work for almost half the cases $(48 \%)$. This proportion varied according to diagnosis, and was higher for silicosis, benign pleural disease, asbestosis, allergic alveolitis, and cancer with fibrosis. Twenty nine per cent of cases were reported as likely to be related to work. For $20 \%$, a relation with work was suspected but considered unlikely. This information was unknown for $3 \%$ of the cases.

Asthma accounted for more than half of all reported cases. All diseases related to asbestos grouped together (asbestosis, mesothelioma, benign pleural disease, and lung and bronchial cancer) represented $16 \%$ of all diagnoses. The proportions of other diseases varied from $1 \%-5 \%$. 
Table 2 Suspected causal agents for occupational asthma from the PROPULSE project, 1992-3

\begin{tabular}{lc}
\hline Agents & $n(\%)$ \\
\hline Isocyanates & $49(17 \cdot 1)$ \\
Flour & $33(11 \cdot 5)$ \\
Wood dust & $31(10 \cdot 8)$ \\
Farm and laboratory animals & $19(6 \cdot 6)$ \\
Plastic, additives, rubber & $19(6 \cdot 6)$ \\
Welding pollutants & $18(6 \cdot 3)$ \\
Fish and shellfish & $10(3 \cdot 5)$ \\
Paints and dyes & $9(3 \cdot 1)$ \\
Multiple chemical products & $9(3 \cdot 1)$ \\
Grain and cereal dust & $8(2 \cdot 8)$ \\
Medical drugs & $7(2 \cdot 4)$ \\
Other chemical compounds & $5(1 \cdot 7)$ \\
Iritants & $5(1 \cdot 7)$ \\
Other & $65(22 \cdot 8)$ \\
Total & $287(100 \cdot 0)$ \\
\hline
\end{tabular}

\section{Asthma}

Asthma cases were younger than the whole group, with a mean age of 39.5 years for men and 36.9 for women. There was a larger proportion of women among cases of asthma than the other diagnoses. Seventy five per cent of workers reported to have asthma were covered by WCB, a higher proportion than for all cases of occupational respiratory diseases (67\%). Eighty different agents were reported as suspected causal agents of asthma. The most frequent were isocyanates, flour, wood dust, and animals (table 2).

Specific rates, by age, sex, and industry, have been calculated only for asthma, because numbers of cases were too small for other diagnostic categories. Unlikely cases were excluded, so as not to inflate the rates inappropriately. The rate of asthma in men $(79 / \mathrm{mil}-$ lion/y) was twice that in women ( $42 / \mathrm{million} / \mathrm{y})$. A small increase in age specific rates was found with age: $55 / \mathrm{million} / \mathrm{y}$ (for 15-24 years), $57 / \mathrm{million} / \mathrm{y}$ (for 25-44 years), and 62/million/y (for 45 years and over). The highest rate of occupational asthma was found for the wood industries (table 3), followed by the food industries where it is associated with baker and pastry cook occupations and, to a lesser extent, with chefs and general cooks, with exposures to flour, fish, and shellfish. In the furniture industry, wood dust was often reported, as were glues, isocyanates, and resins. Those with asthma found in the chemical industry held different jobs with various exposures, notably to medical drugs. The high frequency of asthma in agricultural industries has been related to work with animals and exposure to farm dust. Almost all cases from the automotive vehicles, parts, and accessories

Table 3 Most often reported industries for occupational asthma *

\begin{tabular}{|c|c|c|}
\hline Industry (code) & Cases & $\begin{array}{l}\text { Rate/million/y }{ }^{* *} \\
(95 \% C I)\end{array}$ \\
\hline $\begin{array}{l}\text { Wood industries (251-259) } \\
\text { Food industries (101-109) } \\
\text { Furniture and fixture industries (261-269) } \\
\text { Chemical and chemical products industries (371-379) } \\
\text { Agricultural and related service industries }(011-023) \\
\text { Automotive vehicles industries, sales and service (631-639) } \\
\text { Fabricated metal products industries (301-309) }\end{array}$ & $\begin{array}{r}17 \\
29 \\
8 \\
9 \\
23 \\
22 \\
9\end{array}$ & $\begin{array}{l}691 \cdot 1(402 \cdot 4 \text { to } 1106 \cdot 5) \\
684 \cdot 0(458 \cdot 0 \text { to } 982 \cdot 3) \\
487 \cdot 8(210 \cdot 4 \text { to } 961 \cdot 0) \\
376 \cdot 6(172 \cdot 4 \text { to } 714 \cdot 6) \\
328 \cdot 7(208 \cdot 3 \text { to } 493 \cdot 0) \\
315 \cdot 6(197 \cdot 8 \text { to } 477 \cdot 9) \\
293 \cdot 2(134 \cdot 2 \text { to } 556 \cdot 4)\end{array}$ \\
\hline
\end{tabular}

*Unlikely cases were excluded for the calculation of rates.

$\star \star$ Number of employees (excluding unemployed people) are used as denominators because data on labour force (including unemployed people) were not available for detailed types of industry. Denominators came from reference 11 with the exception of agricultural industry that used reference 10 . industries, sales and service came from motor vehicle repair shops (painters and mechanics accounted for $57 \%$ of all reported cases of asthma related to isocyanates). Cases from fabricated metal products were associated with the job titles of welder and oxygen cutter.

\section{Others diseases}

All cases of silicosis were men with a mean age of $56 \cdot 7$ years. Silicosis was reported among various occupations, particularly those associated with metal polishing, foundries, and mines. A finding of concern was the occurrence of silicosis among six workers under 40 years of age, the youngest being 26 years old, of whom five were involved in sandblasting activities and one was a foundry worker.

The age at diagnosis of diseases related to asbestos was high (mean age 63.1). Most cases were found among mine workers $(18 \%)$, boat manufacturers, and repairers (12\%), electricians and related workers $(7 \%)$, and plumbers and pipefitters $(7 \%)$.

Allergic alveolitis occurred more often among men (83\%) than women (17\%). Two agents were reported for half of the cases: moulds $(25 \%)$ and isocyanates $(25 \%)$.

Inhalation accidents were classified according to whether they were consistent with reactive airways dysfunction syndrome or not. Reactive airways dysfunction syndrome was found mostly among men (86\%), with a lower mean age than for all men reported with occupational respiratory diseases. Chlorine irritants, isocyanates, and acids were the most often reported causal agents. Each of the remaining inhalation accidents was due to a different agent and occurred in a wide variety of occupations.

Sick building syndrome, mostly reported for occupations related to office work, was the only disease for which the number of cases reported was larger for women than for men, probably in part because of the large proportion of women among office workers. ${ }^{10}$ (Statistics Canada, unpublished data)

Other diseases reported were allergic rhinitis, chronic bronchitis, diseases related to metal exposure, and one case of unconfirmed berylliosis.

\section{CASES NOT COVERED BY THE WORKERS'} COMPENSATION BOARD

Fifteen per cent of reported cases were workers not covered by the WCB, and therefore would not be found in the board's official statistics. The diagnoses associated with these cases were distributed as follows: $68 \%$ asthma, $10 \%$ diseases related to asbestos, and $7 \%$ allergic alveolitis. The following industries were the most often reported for all diagnostic categories: agriculture (31\%), food and beverage products $(9 \%)$, and construction $(7 \%)$. Among the asthma cases, an even larger proportion was associated with agricultural activities $(41 \%)$, with farm animals suspected as the causal agents in $28 \%$. Asthma cases not eligible for compensation benefits were more likely to be reported by allergists ( $16 \%$ of physicians reported $52 \%$ of these cases). 
Table 4 Distributions of diagnoses for PROPULSE cases highly likely related to work, compared with mean number of cases compensated by the WCB

\begin{tabular}{lcc}
\hline & $\begin{array}{l}\text { PROPULSE } \\
\text { highly likely cases } \\
n(\%)\end{array}$ & $\begin{array}{l}\text { WCB annual means } \\
1991-4 \\
n(\%)\end{array}$ \\
Diagnostic categories & $121(56 \cdot 0)$ & $60 \cdot 3(30 \cdot 4)$ \\
\hline Asthma & $43(19 \cdot 9)$ & $68 \cdot 5(34 \cdot 6)$ \\
Diseases related to asbestos & $20(9 \cdot 3)$ & $33 \cdot 8(17 \cdot 0)$ \\
Silicosis & $16(7 \cdot 4)$ & $1 \cdot 8(1 \cdot 0)$ \\
Allergic alveolitis & $6(2 \cdot 8)$ & $5(2 \cdot 5)$ \\
Inhalation accident (RADS) & $0(0)$ & $1 \cdot 5(0 \cdot 8)$ \\
Byssinosis & $0(0)$ & $19 \cdot 3(9 \cdot 7)$ \\
Obstructive diseases & $10(4 \cdot 6)$ & $8(4 \cdot 0)$ \\
Others & $216(100 \cdot 0)$ & $198 \cdot 2(100 \cdot 0)$ \\
Total & &
\end{tabular}

RADS = reactive airway dysfunction syndrome.

\section{COMPARISON WITH QUÉBEC COMPENSATION} STATISTICS

The comparison of highly likely cases from PROPULSE and the annual mean number of compensated cases from the WCB (1991-4) showed quite different distributions of diseases (table 4). Twice as many cases of asthma and eight times the number of cases of allergic alveolitis were reported to PROPULSE compared with compensated cases. The number of reported cases of reactive airways dysfunction syndrome was about the same in both systems. For all other diagnoses, the number of compensated cases was larger than those reported to PROPULSE, particularly for obstructive diseases, a diagnosis for which no case was reported as highly likely to be related to work, while a mean annual number of 19 cases were accepted for disability benefits.

The main causal agents for compensated cases of asthma are generally the same as those suspected for cases reported to PROPULSE with the exception of farm animals, which are absent from compensation data but are suspected among $12 \%$ of cases in PROPULSE. Farm animals could be a proxy for the sensitising agent as specific allergens might not be identified in the early phase of investigation. Also, occupational health problems among agricultural workers are probably underreported in compensation statistics because many of them are not covered by WCB.

\section{Discussion}

\section{REPORTING SYSTEM}

The response rate of physicians was interpreted as good for a voluntary participation reporting system compared with the British Colombia Registry (38\%), ${ }^{4}$ and with SENSOR Massachusetts, (about 57\%) (unpublished SENSOR data, Massachusetts, 1993). For the first three years of operation, SWORD reported a higher participation rate for thoracic physicians $(83 \%)$ and a mean rate of monthly returns of $63 \%$ for all participating physicians, ${ }^{3}$ similar to that found in PROPULSE.

There is concern about validity of the information obtained from this type of surveillance system. As with SWORD, we did not specify reporting criteria for each disease for reasons similar to those already stated by others, ${ }^{23}$ in particular, the difficulty of having specific criteria for diseases with variable clinical manifestations, and the importance of a simple reporting procedure to maintain physicians' interest in the project.

A possible threat to validity is the tendency to attribute disease to well known causal agents, particularly in the early stages of medical investigation. For example, isocyanates notorious for their strong sensitising effects, may be more readily associated with occupational asthma than some other agents not yet reported in the literature. None the less, even compensated cases probably share a similar bias, and a surveillance system such as PROPULSE, without stringent requirements for reporting, may help identify new hypotheses to explore the field of occupational respiratory diseases.

\section{COMPARISON WITH OTHER SURVEILLANCE} SYSTEMS

Comparison of surveillance data among countries should be made with caution because reporting systems vary, particularly for the definition of diseases, the specialisation of reporting physicians, the characteristics of the population under study, and the different systems of compensation. None the less, a major similarity with other systems is the high proportion of reported cases of asthma; this has been attributed to a better recognition of this health problem and the increasing number of new sensitising agents used in the workplace. $^{2-414}$ In PROPULSE, this proportion was higher ( $63 \%$ of all diagnoses), than in British Colombia (50\%), ${ }^{4}$ and the United Kingdom $(26 \%-28 \%) .^{23}$ Possible explanations could be that in PROPULSE physicians with expertise in occupational asthma collaborated more actively than chest physicians with special expertise in pneumoconioses or other chronic pulmonary diseases, also allergists participated as sentinel physicians. Isocyanates were the most commonly suspected agents in PROPULSE, as in SWORD, SHIELD, and SENSOR. ${ }^{3515}$ In the British Columbia registry, also based on the SWORD model, western red cedar was more frequent than isocyanates, probably because the forest and wood industries are the main employers in that area. ${ }^{4}$

Although silicosis was probably underreported in PROPULSE, its occurrence among young workers (under 40 years) involved in sandblasting activities emphasises the importance of the problem of exposure to this very harmful operation. The United Kingdom was the first nation to officially ban the use of silica in this process as early as 1950; in 1974, the National Institute for Occupational Safety and Health (NIOSH) recommended banning this industrial process and published an alert on the subject in 1992.16 Published data from SENSOR indicated that silicosis is still an occupational disease worthy of concern with cases reported in workers exposed for less than 10 years, ${ }^{17}$ data similar to those in PROPULSE.

\section{COMPARISON WITH QUÉBEC COMPENSATION} STATISTICS

The different distribution of reported cases of occupational respiratory diseases in 
PROPULSE compared with that of the WCB might be due to several factors. Asthma presented the largest difference, PROPULSE reporting twice as many cases. This probably reflects an overreporting to PROPULSE (due to early reporting of diseases) as well as an underreporting to the WCB-for example, workers not covered by the board, those who choose not to apply for compensation, or those who do not complete the procedures. Further investigation is needed to clarify this point.

Reactive airways dysfunction syndrome is not frequent in either system and we suspect that the syndrome is underreported in both data sources, because it is less often recognised by workers and physicians. If the condition develops after an accident in the workplace, the worker would probably be seen as an emergency and not necessarily present to chest physicians or allergists reporting to PROPULSE. The condition would then probably be recorded in the WCB files as an accident and not as an occupational respiratory disease.

We suspect that most of the compensated cases of chronic obstructive pulmonary disease reported in 1991-4 originated from a single large plant where an extensive study of work related respiratory diseases took place before this project, and that this accounts for the difference between the two sources.

Diseases related to asbestos and silicosis were less often reported to PROPULSE than to the WCB. These diseases are probably more likely to be reported to the WCB and to be accepted for disability benefits because they are specifically related to work and they are well known occupational diseases. The ongoing systematic screening for these diseases in some industrial sectors like mines, enhanced the likelihood of being reported to the board. The lower participation of chest physicians specialising in pneumoconioses in PROPULSE probably contributed to the smaller number of cases in our reporting system.

Data from PROPULSE have shown that about $15 \%$ of reported cases could not be found in official statistics on occupational respiratory diseases, suggesting that compensation data cannot be relied on as the sole source of data for surveillance.

Also, the analysis of reported cases generated by the PROPULSE system has resulted in public health interventions for the preven- tion of silicosis associated with sandblasting and of occupational asthma from the use of isocyanates in automobile repair shops.

In summary, a reporting procedure such as PROPULSE can be implemented as part of a surveillance system. However, further analyses are under way to determine more precisely the characteristics that an ongoing active reporting system should have in Québec, to supplement existing sources of data and provide a better understanding of the occurrence of occupational respiratory disease.

We thank all the physicians who participated in the project in reporting cases and returning the monthly reporting forms; Drs reporting cases and returning the monthly reporting forms; Drs Jean Bourbeau, Benoît Laramee, Pierre Ernst, Denis Laliberte, Jean-Luc Malo, and Pierre Séguin for their comments on the manuscript and their participation in the development of the project; Drs Monique Rioux and Jules Turcot from the WCB for their comments; and Dr Susan Stock for her support in reviewing the manuscript. This project was partially funded by the Comm

1 Seaton A. A short history of occupational lung diseases. In: Morgan WKC, Seaton A, eds. Occupational lung diseases. Philadelphia: W B Saunders, 1995:1-8.

2 Meredith SK, Taylor VM, McDonald JC. Occupational respiratory disease in the United Kingdom 1989: a report to the British Thoracic Society and the Society of Occupational Medicine by the SWORD project group. Br f Ind Med 1991;48:292-8.

3 Meredith SK, McDonald JC. Work-related respiratory disease in the United Kingdom, 1989-92: report on the SWORD project. Occup Med 1994;44:183-9.

4 Contreras GR, Rousseau R, Chan-Yeung M. Occupational respiratory diseases in British Columbia, Canada in 1991. Occup Environ Med 1994;51:710-2.

5 Gannon PFG, Burge PS. The SHIELD scheme in the West Midlands region, United Kingdom. $\mathrm{Br} F$ Ind $\mathrm{Med}$ 1993;50:791-6.

6 Baker EL. Sentinel event notification system for occupational risks (SENSOR): the concept. Am $\mathcal{f}$ Public Health 1989;79(suppl): 18-20.

7 Matte TD, Hoffman RE, Rosenman KD, Stanbury $M$. Surveillance of occupational asthma under the SENSOR model. Chest 1990;98(suppl):173S-8S

8 Statistics Canada, Standards Division. Standard occupational classification 1980. Division. Standard occupa-
Ottawa: SCSD, 1991 tional classification

9 Bureau de la statistique du Québec. Classification des activités économiques du Québec. Québec: BSQ, 1984.

10 Statistics Canada. Labor force annual averages 1993. Ottawa SC, 1994. (Catalogue 71-220 annual.)

1 Statistics Canada. Employment, earnings and hours. Ottawa: SC, 1992. (Catalogue 72-002 monthly.)

12 Pearson ES, Hartley HO, eds. Biometrika tables for statisticians. Vol I. Cambridge: Cambridge University Press, 1954:203.

13 Statistics Canada. Health status of Canadians: report of the 1991 general social survey. Ottawa: SC, 1994. (CS11612E no 8.)

14 Chan-Yeung M, Malo J-L. Aetiological agents in occupational asthma. Eur Respir f 1994;7:346-71.

15 Reilly MJ, Rosenman KD, Watt FC, Schill D, Stanbury M Trimbath LS, et al. Surveillance for occupational asthma-Michigan and New Jersey, 1988-92. MMWR CDC Surveill Summ 1994;43(SS-1):9-17.

16 CDC. NIOSH Alert. Request for assistance in preventing silicosis and deaths from sandblasting. Cincinnati: USDHHS National Institute for Occupational Safety and Health, 1992. (Publ no 92-102.)

17 Reilly MJ, Rosenman KD, Watt FC, Stanbury M, Valiante DJ, Helmus LE, et al. Silicosis surveillance-Michigan, DJ, Helmus LE, et al. Silicosis surveillance-Michigan,
New Jersey, Ohio, and Wisconsin, 1987-90. MMWR NDC Surveill Summ 1993;42(SS-5):23-8. 